\title{
The Kinetics of Secretion From Permeabilized Human Neutrophils: Release of Elastase and Correlations With Other Granule Constituents and Right Angle Light Scatter
}

\author{
James E. Smolen, Sally Jo Stoehr, Alexis E. Traynor, and Larry A. Sklar \\ Division of Pediatric Hematology-Oncology, University of Michigan Medical School, Ann Ar- \\ bor (J.E.S., S.J.S.), and Department of Immunology, Scripps Clinic and Research Founda- \\ tion, La Jolla, California (A.E.T., L.A.S.)
}

\begin{abstract}
We have previously reported that human neutrophils can be permeabilized with the cholesterol-complexing agent digitonin. These permeabilized cells can be induced to secrete lysosomal constituents when exposed to micromolar levels of free $\mathrm{Ca}^{2+}$, a process that is enhanced by certain guanine nucleotides. We examined the kinetics in this system by employing both direct and indirect measures of secretion. A continuous, fluorescent assay of elastase permits real-time monitoring of secretion from azurophil granules. The kinetics of elastase release proved to be rapid, beginning within 3-10 sec and reaching a maximum at 1-2 min. Changes in the $\mathrm{Ca}^{2+}$ concentration did not affect the "lag period" for release. A comparison of the $\mathrm{Ca}^{2+}$ dose-response curves for release of the various granule constituents indicated that elastase was being secreted along with other contents of the azurophil granules. Changes in right angle light scatter (RLS), which have been shown to correlate closely with secretion, also commenced rapidly after the addition of $\mathrm{Ca}^{2+}$; when measured simultaneously, both the $\mathrm{Ca}^{2+}$ dose-response characteristics for changes in RLS and elastase release were very similar. Changes in RLS could be halted within 5 sec by excess EGTA and restarted promptly by repletion with secretory concentrations of $\mathrm{Ca}^{2+}$. In addition, neomycin, a phospholipase $\mathrm{C}$ inhibitor, profoundly diminished degranulation as monitored by RLS and end-point techniques. A continuous assay employing 9-aminoacridine self-quenching as a measure of secretion proved far less satisfactory, but, nonetheless, produced similar kinetics and dose-response characteristics. These data thus suggest that secretion of granule constituents from permeabilized neutrophils takes place rapidly and that the kinetics are comparable to those observed with intact cells.
\end{abstract}

Key words: elastase, neomycin

\section{INTRODUCTION}

Studies of stimulus-response coupling, namely those mechanisms whereby receptor-ligand interactions are translated into cellular responses, have benefited from the recent availability of permeabilized cell systems. In these systems, the intracellular space can be reconstituted ad libitum and putative second messengers can be directly applied. We have shown that human neutrophils can be permeabilized with saponin or digitonin, both cholesterol-complexing agents, and that the permeabilized cells can be induced to secrete granule constituents by $\mathrm{Ca}^{2+}$ alone $[1,2]$. This process does not require the presence of cytochalasin B or any other cofactors. We have also reported that secretion is accompanied by the incorporation of a granule membrane marker, Mol, into the plasma membrane of the permeabilized cell $[3,4]$. Finally, we have shown that in the absence of receptorligand interactions, secretion from permeabilized neutro- phils can be enhanced, and $\mathrm{Ca}^{2+}$ requirements reduced, by the presence of GTP, Gpp(NH)p, and GTP- $\gamma$-S, implicating the involvement of a G-protein(s) in secretion [5].

While $\mathrm{Ca}^{2+}$-induced secretion from permeabilized neutrophils appeared to be physiologic with respect to extent and time course (being complete within 5-10 min), no data with respect to the short-term kinetics of the release response were available. This problem can be addressed by using the continuous spectroscopic assay for elastase, which permits the first 1-2 min of secretion to be examined in detail [6]. Right angle light scatter (RLS) and 9-aminoacridine self-quenching were also em-

Received April 16, 1986; accepted July 9, 1986.

Reprint requests: James E. Smolen, Division of Pediatric Hematology-Oncology, University of Michigan Medical School, Ann Arbor, MI 48109. 
ployed as indirect measures of azurophil granule secretion $[7,8]$ over the same period. Using these systems, we examined the kinetics of $\mathrm{Ca}^{2+}$-induced granule discharge from permeabilized neutrophils. This secretion was also compared with release of other granule constituents.

\section{MATERIALS AND METHODS Reagents}

9-Aminoacridine, Mg-ATP, cytochalasin B, neomycin sulfate, and digitonin were purchased from Sigma Chemical Company, (St. Louis, MO). MeO-Suc-Ala-Ala-ProVal-MCA was purchased from Peninsula Laboratories, Inc., (San Carlos, CA). All other materials were reagent grade.

\section{Preparation of Cell Suspensions}

Neutrophils were obtained from fresh human blood by a modification of the method of Berkow et al [9] and were prepared for these studies as previously described [10]. For some studies of right angle light scatter and 9aminoacridine self-quenching, Hypaque-Ficoll gradients [11] were employed as previously described $[1-5,8]$. Before permeabilization, the cells were washed once and resuspended in Buffer $\mathrm{K}(100 \mathrm{mM} \mathrm{KCl}, 20 \mathrm{mM} \mathrm{NaCl}, 1$ mM EGTA, and $30 \mathrm{mM}$ HEPES, pH 7.0).

\section{Neutrophil Permeabilization}

Permeabilization was performed as previously described [2-5] with minor modifications. In essence, stock solutions of digitonin $(1 \mathrm{mg} / \mathrm{ml}$ in buffer $\mathrm{K})$ were prepared daily. Neutrophils $\left(25 \times 10^{6} / \mathrm{ml}\right)$ suspended in Buffer $\mathrm{K}$ were preincubated for $10 \mathrm{~min}$ at $37^{\circ}$. Incubation was at $37^{\circ}$ for $25 \mathrm{~min}$ with $15 \mu \mathrm{g} / \mathrm{ml}$ digitonin for elutriated cells and $10 \mu \mathrm{g} / \mathrm{ml}$ digitonin for cells isolated by Hypaque-Ficoll; the cell suspension was mixed every 5 min. These two conditions led to comparable degrees of permeabilization.

\section{Lysosomal Enzyme Release}

Following permeabilization, neutrophils were spun down and resuspended in Buffer $\mathrm{K}$ at a concentration of $5 \times 10^{6} / \mathrm{ml}$ and then incubated with the desired concentration of $\mathrm{Ca}^{2+}$ at $37^{\circ}$ for $10 \mathrm{~min}$; free $\mathrm{Ca}^{2+}$ was determined for the buffer by using a $\mathrm{Ca}^{2+}$ electrode. Cells incubated without calcium and unpermeabilized neutrophils were employed as routine controls. The cell suspensions were then centrifuged at $750 \mathrm{~g}$ for $10 \mathrm{~min}$. Aliquots of the supernatants were taken for standard determinations of $\beta$-glucuronidase (12; an enzyme found exclusively in azurophil granules), lysozyme (13; an enzyme found in both specific and azurophil granules), vitamin B12 binding protein (14; a component of specific granules alone), and LDH (15; a cytosolic enzyme), activities.

\section{Elastase}

The procedure of Sklar et al [6] was employed with minor modifications. Permeabilized neutrophils $\left(2 \times 10^{6} \%\right.$ $\mathrm{ml}$ ) were suspended in the presence of $2 \times 10^{-5} \mathrm{M} \mathrm{MeO}$ Suc-Ala-Ala-Pro-Val-MCA in Buffer K. The cell suspension was equilibrated for $5 \mathrm{~min}$ at $37^{\circ} \mathrm{C}$ prior to the addition of $\mathrm{Ca}^{2+}$. Fluorescence measurements were performed using an SLM 4800 computer-interfaced spectrofluorimeter with continuous data acquisition. The cell suspension was held in a plastic cuvette placed in a thermostatted sample chamber equipped with a magnetic stirrer and direct injection system. The time required for sample injection and mixing was $1 \mathrm{sec}$.

\section{Right Angle Light Scatter (RLS)}

The procedure of Sklar et al [7] was employed with minor modifications. Permeabilized neutrophils were suspended in Buffer $\mathrm{K}\left(2 \times 10^{6} / \mathrm{ml}\right)$ and equilibrated at $37^{\circ} \mathrm{C}$ for $5 \mathrm{~min}$ prior to the addition of $\mathrm{Ca}^{2+}$. RLS measurements were performed using either a PerkinElmer 650-10S spectrofluorimeter equipped with a thermostatted cuvette holder and magnetic stirring or the above-mentioned SLM 4800. Continuous measurements were obtained using excitation and emission wavelengths

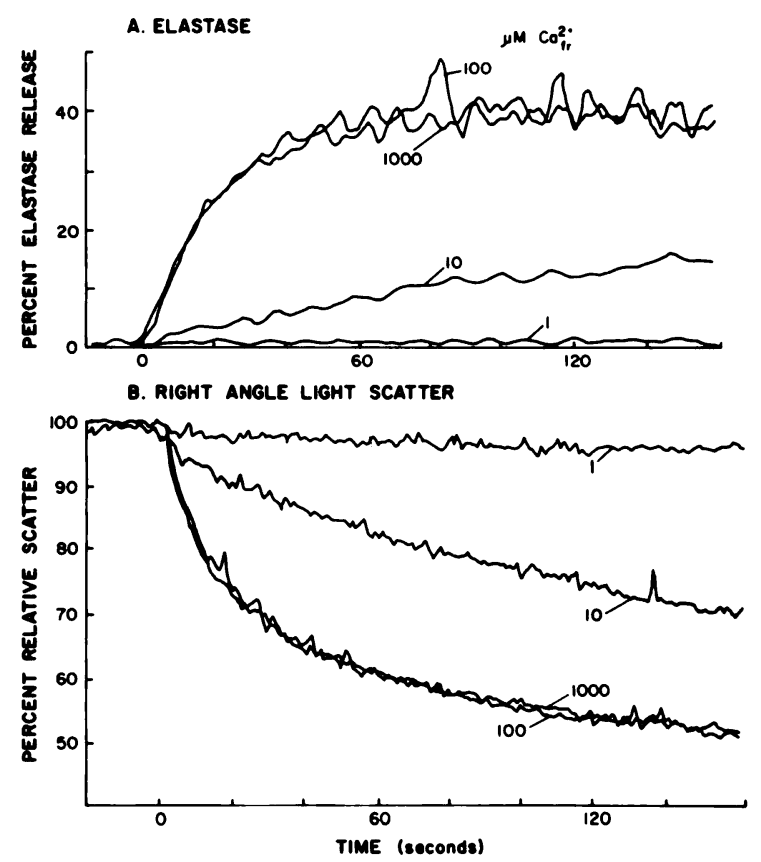

Fig. 1. Simultaneous measurements of elastase rolease and right angle light scatter in permeabilized human neutrophils. Elastase release and RLS were monttored simultaneously as outlined in Materials and Methods. Total cellular elastase content was determined following disruption with Triton X-100. At time 0 , the indicated concentrations of $\mathrm{Ca}^{2+}(1,10,100$, and $1000 \mu \mathrm{M})$ were added. Elastase release is shown in A while RLS is shown in B. The results shown are from a single typlcal experiment. 
of $460 \mathrm{~nm}$ in the Perkin-Elmer system. When simultaneous measurements of RLS and elastase release were made in the SLM 4800, two emission channels were monitored. One was set at $380 \mathrm{~nm}$, the excitation wavelength, to measure RLS, while the other was set to $490 \mathrm{~nm}$, to measure elastase activity. The results obtained for RLS were indistinguishable at these two wavelengths.

\section{9-Aminoacridine Self-Quenching}

The procedure of Smolen et al [8] was employed with the following modifications. Permeabilization was performed in the presence of 9-aminoacridine $(100 \mu \mathrm{M})$ and $1 \mathrm{mM} \mathrm{Mg}$-ATP (to maintain granule $\mathrm{pH}$ gradients). The cells were washed once in Buffer $\mathrm{K}$ plus $1 \mathrm{mM} \mathrm{Mg-ATP}$ and the fluorescence was monitored continuously in the same medium.

\section{RESULTS}

In some of these studies, neutrophils were prepared by elutriation, designed to dispense with the potentially disruptive hypotonic lysis step usually employed for the elimination of erythrocytes. These cells were more resistant to permeabilization than those prepared by HypaqueFicoll centrifugation, Dextran sedimentation, and hypotonic lysis. Consequently, the concentration of digitonin was increased from 10 to $15 \mu \mathrm{g} / \mathrm{ml}$ to obtain efficient permeabilization.

\section{$\mathrm{Ca}^{2+}$ Induces Efficient Degranulation From Permeabilized Neutrophils}

Figure 1A shows a representative experiment in which permeabilized neutrophils were exposed to various concentrations of $\mathrm{Ca}^{2+}$ fr and the release of elastase was continuously monitored. There was also a close correlation between the kinetics of secretion and changes in RLS (Fig. 1B). These two responses could be measured simultaneously in the SLM 4800 spectrofluorimeter. As can be seen, both measures of secretion were saturated at high concentrations $(>100 \mu \mathrm{M})$ of $\mathrm{Ca}^{2+}$; Jow concentrations of $\mathrm{Ca}^{2+}(1 \mu \mathrm{M})$ were inactive. A threshold concentration $(10 \mu \mathrm{M})$ produced similar intermediate responses that, unlike those seen at $>100 \mu \mathrm{M}$, did not reach completion after $2 \mathrm{~min}$. These data show that elastase release and changes in RLS were initiated after a lag period of only 3-10 sec; maximal responses were obtained after 1-2 min. Neither the "lag period" nor the time at which maximal release was obtained were markedly dependent upon the concentration of $\mathrm{Ca}^{2+}$ employed. The presence of cytochalasin B $(5 \mu \mathrm{g} / \mathrm{ml})$ had no effect upon these responses (data not shown; see also ref. [2]).

While the threshold concentration of $\mathrm{Ca}^{2+}$ at which elastase secretion was first observed varied from day to day, the dose-response curve was always very steep. Figure 2 shows the compiled results from five separate experiments in which elastase release was monitored. As can be seen, the dose-response curve was very steep, with secretion commencing at $20 \mu \mathrm{M} \mathrm{Ca}^{2+}$ and becoming maximal at $40 \mu \mathrm{M}$.

We compared secretion of elastase with the release of a number of other cellular constituents. As can be seen in Figure 3, increasing concentrations of $\mathrm{Ca}^{2+}$ reduced the amount of the cytoplasmic enzyme LDH released during the course of the experiment; this is apparently due to partial resealing of the cells by $\mathrm{Ca}^{2+}$, which we have previously reported [16]. The azurophil granule enzyme, $\beta$-glucuronidase, like elastase, was released by 20-40 $\mu \mathrm{M} \mathrm{Ca}^{2+}$. Lysozyme, an enzyme found in both the specific and azurophil granules, was secreted at similar or slightly lower concentrations. In contrast, vitamin B12 binding protein, a constituent of specific granules, was released at substantially lower concentrations, as low as $3 \mu \mathrm{M} \mathrm{Ca}^{2+}$.

\section{Reversibility of Initiation of Degranulation}

Right angle light scatter (RLS) was also used as a convenient way to monitor reversibility of degranulation. As can be seen in Figure 4A, prompt decreases in RLS

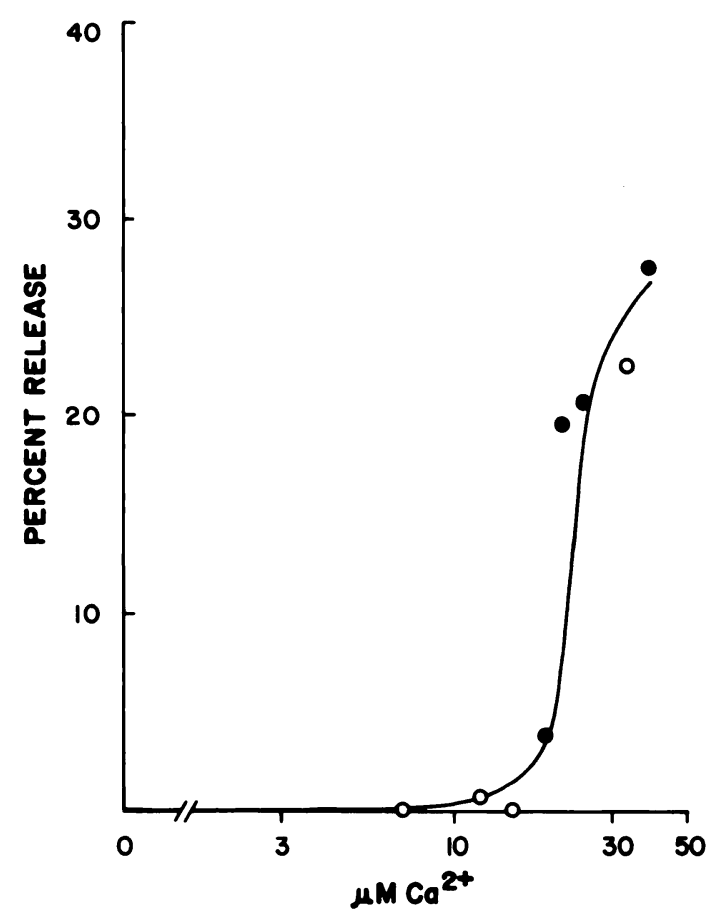

Fig. 2. The effects of free $\mathrm{Ca}^{2+}$ on elastase release from permeabilized human neutrophils. Human neutrophils were permeabilized and elastase release was measured as outlined in Materials and Methods and the legend to Figure 1. Maximal elastase release is shown as a function of free $\mathrm{Ca}^{2+}$ concentration. The data are a compilation of five separate experiments $(n=2-9$, for each point) and solid symbols indicate those points that are significantly greater than baseline $(p<$ 0.05; paired Student's t-test). 


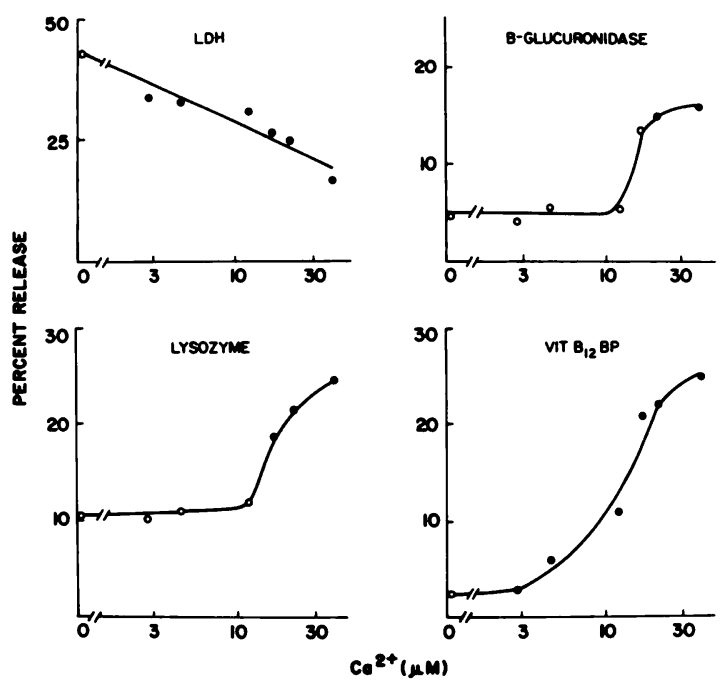

Fig. 3. The effects of free $\mathrm{Ca}^{2+}$ on release of cellular constituents from permeabilized human neutrophils. Human neutrophils were permeabilized and the release of cellular constituents was measured as outlined in Materials and Methods. Release is shown as a function of free $\mathrm{Ca}^{2}+$ concentration for $\mathrm{LDH}, \beta$ glucuronidase, lysozyme, and vitamin B12 binding protein. The data are from five experiments (three for $\beta$-glucuronidase), and solid symbols indicate those points that are significantly greater than baseline ( $p<0.05$; paired Student's t-test).

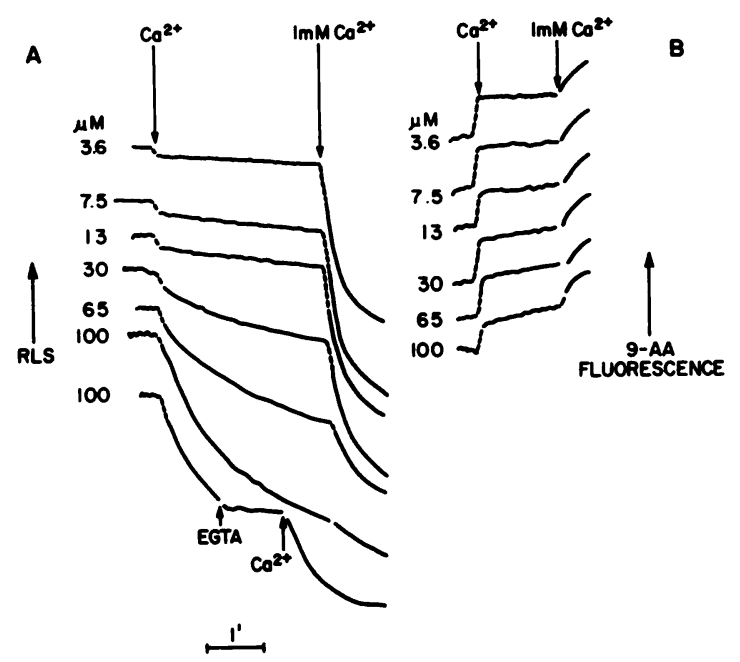

Fig. 4. Changes in right angle light scatter and 9-aminoacridine fluorescence induced by $\mathrm{Ca}^{2+}$ in permeabilized neutrophils. Human neutrophils were loaded with 9-aminoacridine during permeabilization; RLS and 9-aminoacridine fluorescence were separately monitored as outlined in Materials and Methods. At the time indicated by the arrow on the left, micromolar concentrations of $\mathrm{Ca}^{2+}$ (designated on the left margin) were added. Saturating $\mathrm{Ca}^{2+}(1 \mathrm{mM})$ was added later in each run, as indicated by the arrow on the right. The results were obtained from a representative experiment, of which four were performed. were observed following the addition of secretory concentrations of $\mathrm{Ca}^{2+}$. These changes commenced within seconds, as rapidly as could be measured. When saturating $\mathrm{Ca}^{2+}$ was added at the end of the experiment, a further drop in RLS occurred that was inversely proportional to the initial stimulus concentration; indeed, the total changes in RLS at the end of the 4-min runs were constant for all conditions. The bottom curve in Figure 4A shows that changes in RLS could be stopped within 5 sec by the addition of EGTA and restarted promptly by the addition of excess $\mathrm{Ca}^{2+}$. These data thus show that EGTA and/or $\mathrm{Ca}^{2+}$ have free access to the permeabilized neutrophils under all conditions.

\section{9-Aminoacridine Fluorescence as a Measure of Degranulation}

We have previously reported the use of 9-aminoacridine self-quenching as an indirect probe of azurophil granule secretion [8]. These acidic granules incorporate 9-aminoacridine to such an extent that self-quenching of the probe occurs; release of 9-aminoacridine as a result of secretion results in an increase in fluorescence. In order to attempt to maintain the $\mathrm{pH}$ gradient required for this technique, Mg-ATP was present at all times. As shown in Figure 4B, the addition of $\mathrm{Ca}^{2+}$ to permeabilized neutrophils loaded with 9-aminoacridine produced two distinct responses. The first was a very rapid increment in fluorescence that was obtained even with submicromolar concentrations of $\mathrm{Ca}^{2+}$ and was thus not related to secretion of either azurophil or specific granules. Immediately following this increment, the fluorescence increased in a $\mathrm{Ca}^{2+}$-dependent manner; this rise in slope seemed to commence within seconds. However, this technique is clearly not satisfactory with permeabilized cells. The signal was very weak and easily obscured by both the prompt increment and rising baselines. Saturating concentrations of $\mathrm{Ca}^{2+}$ added at the end of the experiment resulted in an additional rise in fluorescence. As with RLS, the total rise in signal following the prompt increment was approximately constant under all conditions.

In view of the apparent importance of phospholipase $C$ in stimulus-response coupling, we examined an inhibitor of this enzyme, neomycin, for its effects on secretion. As can be seen in Figure 5, concentrations of neomycin from 0.3 to $1.0 \mathrm{mM}$ virtually abolished $\mathrm{Ca}^{2+}$-induced changes in RLS. Similar inhibition of secretion was also found when the endpoint assays were employed (data not shown).

\section{DISCUSSION}

These data provide the first report of the kinetics of granule discharge from permeabilized neutrophils using 


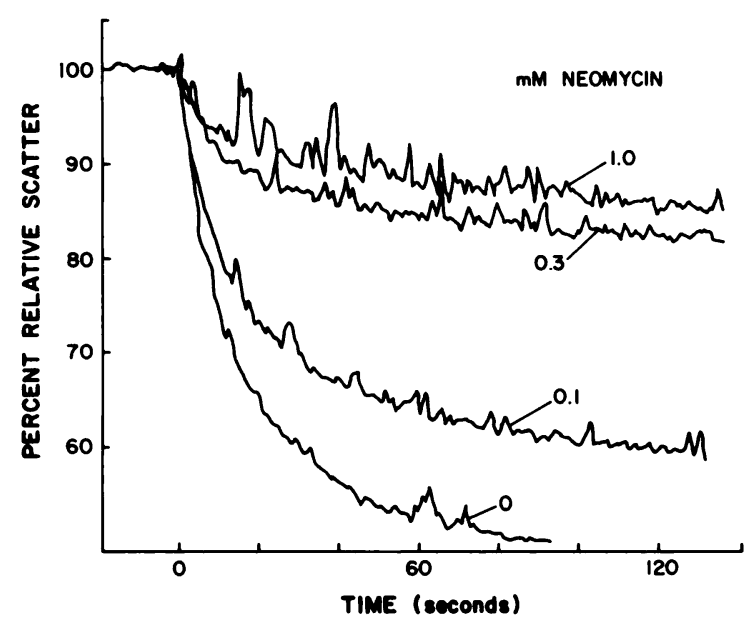

Fig. 5. Effect of neomycin on the RLS response of permeabilized neutrophils. Permeabilized neutrophils were incubated with the indicated concentrations of neomycin sulfate and exposed to $200 \mu \mathrm{M} \mathrm{Ca}{ }^{2+}$ at time O. RLS was continuously monitored as described above.

both direct and indirect methods. The release of elastase and changes in RLS were rapid, with lag periods of 3-10 sec. Thirty to forty percent of the total cellular elastase was secreted after a 2-min incubation with $\mathrm{Ca}^{2+}$. Both the short lag period and total release of elastase were comparable to those observed for intact cells stimulated with $\mathrm{N}$-formylated chemotactic peptides in the presence of cytochalasin B $[6,7,17]$. However, the time required for maximal release of elastase was 1-2 min in the permeabilized neutrophils, which may be somewhat longer than that observed with intact cells. Nonetheless, the kinetics were comparable and suggest that $\mathrm{Ca}^{2+}$-induced secretion in the permeabilized cell represents a normal physiologic response to stimulation (Fig. 1).

The dose-response data shown in Figure 3 strongly suggest that elastase and changes in RLS are associated at least with azurophil granules. Both of these measures appeared to be strongly correlated with that of $\beta$-glucuronidase and, to a lesser extent, lysozyme; both of these latter enzymes are known to be localized in azurophil granules. The specific granule constituent vitamin B12 binding protein may have begun to be secreted at somewhat lower $\mathrm{Ca}^{2+}$ concentrations than required for elastase release or RLS changes. These data thus provide additional support for an azurophil granule localization for elastase and for differential secretion of the two granule types [1-5,17-19], even in the absence of cytochalasin B. Differential secretion is also observed with the two permeabilization systems used in these laboratories, since release of $\beta$-glucuronidase can be obtained if the cells are permeabilized with digitonin [2], but not with saponin [1].

In contrast to these results, experiments employing 9aminoacridine were disappointing. This technique is based upon the maintenance of a pH gradient across the granule membrane, the disruption of which is likely during permeabilization;. This factor may account for the very weak signal that was observed, in spite of the inclusion of Mg-ATP in the medium to help maintain the $\mathrm{pH}$ gradient. Two components of the signal were observed: first, an immediate increase that could be obtained at very low concentrations of $\mathrm{Ca}^{2+}$ and, second, a gentle increase in fluorescence that could be found at higher concentrations. This latter portion of the signal varied with $\mathrm{Ca}^{2+}$ in a manner that correlated with azurophil granule secretion. The first, rapid increment did not appear to be a dilution artifact and may be due to activation of a Ca ${ }^{2+} / \mathrm{H}^{+}$exchange system.

Two additional observations are worthy of note. First, secretion induced by $\mathrm{Ca}^{2+}$ could be halted within $5 \mathrm{sec}$ by excess EGTA. This, combined with the ability to restart secretion with $\mathrm{Ca}^{2+}$, suggests that $\mathrm{Ca}^{2+}$ is a requirement for degranulation at all times during this process. These data also confirm that $\mathrm{Ca}^{2+}$ only partially reseals the cells [16], which remain permeable to EGTA even in the presence of the divalent cation. Thus, it is possible to freely alter the "intracellular" concentration of small solutes in the presence or absence of $\mathrm{Ca}^{2+}$.

The second observation, namely the inhibition of $\mathrm{Ca}^{2+}$ induced secretion afforded by neomycin, suggests a possible role for phospholipase $\mathrm{C}$ activity. There is some evidence that this antibiotic is a competitive inhibitor of phosphatidylinositol-specific phospholipase C $[19,20]$. Concentrations of the drug comparable to those employed here have been shown to inhibit secretion from mast cells [21] and inositol trisphosphate $\left(\mathrm{IP}_{3}\right)$ production by permeabilized pancreatic acinar cells [22]. Whether the enzyme or its products, $\mathrm{IP}_{3}$ and diacylglycerol, are participating in degranulation by permeabilized neutrophils is currently under investigation.

In summary, we have shown that the kinetics of elastase release and changes in RLS using permeabilized human neutrophils are comparable to those observed for intact cells. Furthermore, these two measures correlated closely with release of other azurophil granule constituents. These data thus provide further evidence that the permeabilized cell system can be used as a model for stimulus-response coupling in vivo.

\section{ACKNOWLEDGMENTS}

This work was supported by NIH grants AM 32471 (J.E.S.) and AI 19032 (L.A.S.). J.E.S. is a Senior Fellow of the Arthritis Foundation. L.A.S. is an established investigator of the American Heart Association.

\section{REFERENCES}

1. Smolen, J.E., and Stoehr, S.J. Micromolar concentrations of free calcium provoke secretion of lysozyme from human neutrophils permeabilized with saponin. J. Immunol. 134, 1859, 1985. 
2. Smolen, J.E., Stoehr, S.J., and Boxer, L.A. Human neutrophils permeabilized with digitonin respond with lysosomal enzyme release when exposed to micromolar levels of free calcium. Biochim. Biophys. Acta 886, 1, 1986.

3. Smolen, J.E., Todd III, R.F., and Boxer, L.A. Expression of a granule membrane marker on the surface of neutrophils permeabilized with digitonin. Correlations with $\mathrm{Ca}^{2+}$-induced degranulation. Am. J. Pathol. 124, 281, 1986.

4. Smolen, J.E., Todd III, R.F., Boxer, L.A., and Rich, A.M. Calcium induced lysosomal enzyme release from permeabilized human neutrophils results in cell surface expression of specific granule components. Clin. Res. (abstract) 33, 513a, 1985.

5. Smolen, J.E., and Stoehr, S.J. Guanine nucleotides reduce the free calcium requirement for secretion of granule constituents from permeabilized human neutrophils. Biochim. Biophys. Acta (In press).

6. Sklar, L.A., McNeil, V.M., Jesaitis, A.J., Painter, R.G., and Cochrane, C.G. A continuous, spectroscopic analysis of the kinetics of elastase secretion by neutrophils. The dependence of secretion upon receptor occupancy. J. Biol. Chem. 257, 5471, 1982.

7. Sklar, L.A., Oades, Z.G., and Finney, D.A. Neutrophil degranulation detected by right angle light scattering: spectroscopic methods suitable for simultaneous analyses of degranulation or shape change, elastase release, and cell aggregation. J. Immunol. $133,1483,1984$.

8. Smolen, J.E., Korchak, H.M., and Weissmann, G. The kinetics of lysosomal degranulation of human neutrophils as measured by 9-aminoacridine quenching. Biochim. Biophys. Acta 762, 145, 1983.

9. Berkow, R.L., Weisman, S.J., Tzeng, D., Haak, R.A., Kleinhans, F.W., Barefoot, S., and Baehner, R.L. Comparative responses of human polymorphonuclear leukocytes obtained by counterflow centrifugal elutriation and Ficoll-Hypaque density centrifugation. J. Lab. Clin. Med. 104, 698, 1984.

10. Sklar, L.A., Jesaitis, A.J., Painter, R.G., and Cochrane, C.G. The kinetics of neutrophil activation. The response to chemotactic peptides depends upon whether ligand-receptor interaction is ratelimiting. J. Biol. Chem. 256, 9909, 1981.

11. Boyum, A. Isolation of mononuclear cells and granulocytes from human blood. Isolation of mononuclear cells by centrifugation and of granulocytes by combining centrifugation and sedimentation at 1 G. Scand. J. Clin. Lab. Invest. 21, 77, 1968.

12. Brittinger, G.R., Hirschhorn, R., Douglas, S.D., and Weissmann, G. Studies on lysosomes. XI. Characterization of hydrolase-rich fraction from human lymphocytes. J. Cell Biol. 37, 394, 1968.

13. Worthington Enzyme Manual. Freehold, NJ: Worthington Biochem. Co., p. 100, 1972.

14. Smith, G.P., and Peters, T.J. The release of granule components from human polymorphonuclear leukocytes in response to both phagocytic and chemical stimuli. Biochim. Biophys. Acta 719, 304, 1982.

15. Wacker, W.E.C., Ulmer, D.D., and Vallee, B.L. Metalloenzymes and myocardial infarction. II. Malic and lactic dehydrogenase activities and zinc ion concentration in serum. N. Eng. J. Med. 255, 449, 1956.

16. Smolen, J.E., Stoehr, S.J., and Boxer, L.A. Partial resealing of neutrophils previously permeabilized with digitonin. J. Cell Biol. (abstract) 99, 331a, 1984.

17. Smolen, J.E., Korchak, H.M., and Weissmann, G. Initial kinetics of lysosomal enzyme secretion and superoxide anion generation by human polymorphonuclear leukocytes. Inflammation 4, 145, 1980.

18. Bentwood, B.J., and Henson, P.M. The sequential release of granule constituents from human neutrophils. J. Immunol. 124, 885, 1980.

19. Lipsky, J.J., and Lietman, P.S. Aminoglycoside inhibition of a renal phosphatidylinositol phospholipase C. J. Pharmacol. Exp. Ther. 220, 287, 1982.

20. Sagawa, N., Bleasdale, J.E., and Di-Renzo, G.C. The effects of polyamines and aminoglycosides on phosphatidylinositol-specific phospholipase $\mathbf{C}$ from human amnion. Biochim. Biophys. Acta 752, 153, 1983.

21. Cockcroft, S., and Gomperts, B.D. Role of guanine nucleotide binding protein in the activation of polyphosphoinositide phosphodiesterase. Nature 314, 534, 1985.

22. Streb, H., Heslop, J.P., Irvine, R.F., Schulz, I., and Berridge, M.J. Relationship between secretagogue-induced $\mathrm{Ca}^{2+}$ release and inositol polyphosphate production in permeabilized pancreatic acinar cells. J. Biol. Chem. 260, 7309, 1985. 